\title{
NATURALISMO Y HERMENÉUTICA DE LA CONCIENCIA. Una discusión con Juan Arana
}

\author{
Francisco Rodríguez Valls \\ Universidad de Sevilla
}

\begin{abstract}
Resumen: Este ensayo considera las principales tesis del libro La conciencia inexplicada de Juan Arana, en especial la de la inexplicabilidad de la conciencia mediante metodologías naturalistas. Se sostiene la idea de una posible explicación mediante otro tipo de metodología de corte hermenéutico.

Palabras clave: Naturalismo, hermenéutica, consciencia, explicación.

Naturalism and hermeneutics of consciousness. A debate with Juan Arana
\end{abstract}

Abstract: This paper regards the main thesis of the book The unexplained consciousness by Juan Arana, specially the thesis of the inexplicability of consciousness by means of naturalistic methodologies. It is held the idea of a possible explanation through hermeneutical methodologies.

Keywords: Naturalism, Hermeneutics, Consciousness, Explanation.

Recibido: 03/08/2016 Aprobado: 14/09/2016

\section{Introducción}

A finales del año 2015, el profesor Juan Arana ha dedicado un libro al problema de la naturalización de la conciencia (Arana, 2015). En su título sostiene que la conciencia está inexplicada desde el paradigma de la ciencia natural y, en su argumentación, va más allá de esa afirmación postulando que es y seguirá siendo inexplicable según ese mismo paradigma. Arana da importancia a ese hecho por resultarle necesario reservar lo humano, o una 
visión "humanista”, del intento que presume que la ciencia natural algún día explicará todo en términos causales: que reducirá todo a "res extensa" resolviendo en términos materialistas el dualismo cartesiano. Arana expone en su obra los resultados de la ciencia y del paradigma naturalista para ver qué es lo que ha conseguido hasta hoy en ese propósito. Como punto de partida sostiene que la conciencia es el bastión inexpugnable que resiste que el ser humano sea reducido a una máquina más o menos compleja (mecánica, lógica o neuronal) ya que supone una singularidad que de ninguna forma podrá ser completamente objetivada. Para todos los que conocemos la obra de Arana, tan apegada a la ciencia natural, no nos extraña que esa afirmación haya abierto una brecha en sus querencias filosóficas hasta tal punto que le ha llevado a decir que no la hay pero que, si hubiera alguna explicación de ese fenómeno, "la única explicación de la conciencia que podría ser satisfactoria sería la naturalista" (Arana, 2015: 131). No hay explicación posible y, si tuviera que haberla, solo podría ser naturalista. ¿Por qué esa afirmación? ¿No hay formas alternativas de comprender la especificidad de la conciencia de tipo hermenéutico o fenomenológico? Para comprenderlo hay que sumergirse en los presupuestos de qué se entiende por naturalismo y por qué tan ilustre profesor y académico le niega su venia tanto a él como a cualquier otra opción posible.

\section{El programa naturalista}

Entiéndase por naturalismo el intento o programa de investigación que consiste en querer explicar todo fenómeno de la realidad mediante los proce- 
dimientos de la ciencia natural: toda realidad qua realidad es natural y, por ello, afirma el naturalismo, es naturalizable, es decir, "debe" ser reductible a fenómenos físico-químicos o biológicos. Esos procedimientos llevan a pensar que se puede objetivar plenamente todo fenómeno sin que se escape nada que le resulte esencial. La conciencia formaría parte de esos objetivos. Aquí, Arana niega la mayor y afirma que el paradigma y los métodos de la ciencia no pueden dar razón de toda realidad sino de toda aquella que sea objetivable y que la conciencia, por motivos que ahora se verán, no puede serlo. No puede serlo de acuerdo con la propia noción o acercamiento preliminar que Arana hace al término conciencia: “dimensión autotransparente de la vida psíquica, en virtud de la cual el sujeto pensante se convierte en espectador activo de sí mismo" (Arana, 2015: 19). La conciencia es eminentemente subjetualidad que no puede ser registrada apodícticamente en tanto que es un constante trascender los productos que realiza. Se podría registrar lo que la conciencia ha sido, pero no lo que es. Y la conciencia es fundamentalmente no sus obras sino aquel fenómeno que "siendo" trasciende su "estar". Su ser es siempre creador y trascendedor de su propia realidad.

El programa naturalista ha pretendido reducir la conciencia a una máquina de índole mecánica, a una máquina lógica con la inteligencia artificial o a una máquina de carne con las neurociencias. En los tres casos (Arana dedica un capítulo a cada una en su libro) la insuficiencia resulta la misma: una vez analizadas las partes de los mecanismos, de los algoritmos computacionales o de la estructura y las asambleas de neuronas, no hay forma de detectar en ellas la presencia de una conciencia reflexiva. A todas ellas puede aplicarse el argumento del molino que Leibniz expresó en su Monadología y 
que Arana desentraña en el parágrafo 17 de su obra y que, de una forma u otra, va a estar presente a lo largo de toda su crítica al naturalismo. La pregunta de fondo que me surge es la siguiente: jes Arana defensor de algún tipo de dualismo que le prevenga de dar el salto a la opción naturalista que es de por sí monista y reduccionista? Y en su obra hay que deslindar lo que es el campo de la ontología de lo que es el de la teoría del conocimiento.

Arana sostiene una ontología de la unidad de la sustancia, como podemos ver en el siguiente texto:

Un matiz que debe tenerse en cuenta para bieninterpretar mi posición, es que no sostengo que cuerpo y conciencia remitan a realidades distintas, sino a una misma realidad abstraída a partir de dos criterios diferentes (sometimiento a la legalidad natural y autotransparencia), criterios que no se dejan reducir uno a otro, aunque tampoco supone el primero la simple negación del segundo, ni agotan necesariamente entre ambos las posibilidades existenciales de la realidad abstraída (Arana, 2015: 174).

Y para dejarlo más claro aún dice, un par de páginas más adelante, en la 176: "La única explicación es que soma y conciencia son aspectos inseparables de una realidad única”. Y eso para Arana quiere decir una sustancia única ya que en múltiples textos afirma que el error de Descartes no consiste, como pretende señalar Damasio, en separar el pensamiento del cuerpo, sino en haber sustantivado ambos.

Pero una cosa es sostener que la realidad sea única y otra que el acercamiento epistemológico que hay que hacer para aprehenderla responda en su integridad a los parámetros de la ciencia natural: esos procedimientos solo 
pueden dar razón — por opción metodológica de la propia ciencia - de parte de ella. Y eso podría entenderse como dualismo. Arana sostiene ontológicamente una única sustancia, un monismo ontológico, que se convierte en dualismo epistemológico por razón de la limitación del conocimiento humano. El propio autor reconoce esa posibilidad y aclara su posición cuando dice:

Reconozco que mucho de lo dicho en los últimos párrafos me hace vehementemente sospechoso de dualismo, adscripción que no me asusta, pues tampoco es constitutiva de delito. Ahora bien, si hubiera de expresar con justeza mi posición, diría que la conciencia y el resto de lo que constituye la realidad del hombre (cuerpo, organismo, o lo que sea) no se relacionan entre sí como dos sustancias diferentes, sino como aspectos o dimensiones de una realidad única. Si tomamos esta realidad tal cual y la hacemos pasar a través del filtro naturalista, obtenemos una visión parcial de lo humano que se atiene estrictamente a esquemas legaliformes. Podemos llamar "cuerpo" a su contenido (confieso que no se me ocurre una designación mejor), aunque convendría tener presente que el concepto de cuerpo así establecido no hace referencia en particular a lo táctil, impenetrable, extenso, etc., sino más en general a lo reglado, a todo aquello que vemos del hombre bajo el prisma de lo nomológico. Por su parte, "conciencia" no quiere decir alma, espíritu ni cualquier otra noción parecida, aunque tengan rasgos que la aproximan a ellas, sino, de modo paralelo, aquellos aspectos de la realidad humana que conseguimos atrapar cuando prescindimos de todo lo que no sea el mundo interior de las representaciones autotransparentes. No veo problema alguno para que ambas cosas correspondan a una única sustancia, ni que estén estrechísimamente abrazadas y conectadas a través de múltiples lazos (Arana, 2015: 192-193). 
La conciencia no es explicable si se la somete al punto de vista de lo nomológico porque es una realidad nomogónica, es decir, creadora de leyes. Es, por usar una terminología muy antigua, natura naturata naturans y no natura naturata naturata. Esa es la tesis de fondo del autor y que, a mi parecer, desarrolla con solvencia. He de decir que el tema resulta esencial para la visión del hombre y del mundo que se tenga y que Arana consigue explicar por qué lo es. Ahora bien, creo que ese programa "delimitador" de lo que le corresponde al naturalismo y lo que es propio del humanismo hay que reivindicarlo no solo en su vertiente negativa sino en la caracterización "humanista" de la conciencia que puede extraerse de él. Arana da unas cuantas claves para ello aunque creo que no da el paso a la reivindicación de una explicación de la conciencia de un orden diferente por considerarla inviable.

\section{La antropología de la conciencia de Arana}

En su obra, Arana no solo hace una pars destruens del programa omnicomprehensivo naturalista diciendo que no puede explicar "todo", aunque sí dice que puede hacerlo con "casi" todo: exactamente lo único que no puede explicar es la conciencia. Claro que eso tiene otras derivaciones clave que tampoco puede explicar como, por ejemplo, la cuestión de la bondad moral o la búsqueda del valor objetivo. Pero, además de eso, da algunas notas esenciales de qué entiende por conciencia aunque no logre incardinarla en un programa diferente del naturalista ya que, como hemos visto, piensa que solo tal tipo de explicación es explicación propiamente dicha. Su única 
forma válida es la de si... entonces (dado un conjunto de condiciones se deducen unos determinados hechos). Evidentemente la conciencia no funciona bajo ese esquema causal sino que tiene un tipo de causalidad peculiar y propia.

Las notas que, sin hurgar demasiado en el texto, dan razón de la conciencia son las siguientes: autorreferencia e infinitud (p. 108), prescindibilidad e independencia (p. 136), unidad y continuidad (p. 141), extraversión (p. 162) y, por supuesto, es nomogógica (p. 201). Ya que explicar cada una de esas notas requeriría escribir el libro de Arana, cosa que está ya hecha y a disposición del lector, voy a sintetizar en lo esencial sus significados de forma conjunta. Espero no ser simplista en mis enunciados para que mi interlocutor se reconozca en ellos.

En primer lugar, la conciencia no es la conciencia que puede tener un animal sino que es auto-conciencia; es exclusiva - que sepamos- de lo humano. No se niega que el animal sea capaz de captar una información y de dirigir su conducta de acuerdo con ella, es decir, que tenga lo que los analíticos llaman conciencia "fenoménica". Lo que no parece que hay es conciencia de que cuando piensa esa información se dé cuenta de que es él el que está siendo consciente: de que es un yo pensante. La auto-conciencia es, consecuentemente, el correlato concomitante de la conciencia y, cuando el foco se dirige hacia la interioridad, es "el correlato ontológico de la introspección mental”. Eso es lo que Descartes intuyó que no se podía explicar como una máquina a base de engranajes y émbolos por muy sofisticados que fueran y que caracterizó como cogito aunque cometiera el despropósito de sustancializarlo. Esa autoconsciencia implica auto-transparencia (el yo que piensa es 
captado en el acto de conciencia) y es infinita en el sentido en que es fuente de creación continua y siempre va más allá de todo lo que crea (como el rey Midas todo lo convierte en oro menos sus propias manos o el albatros que tiene que posarse en tierra alguna vez durante su vuelo). Eso mismo explica su extraversión. Que sea prescindible e independiente quiere decir que no puede ser explicada por la mera eficacia biológica sino que es un plus en la evolución del que la evolución misma no puede dar cuenta. Pero si en algo insiste Arana es en que la actividad de la conciencia no está hecha únicamente para regirse por leyes sino que es fuente de legalidad sobre sí misma y sobre su hacer: sobre su hacer inmanente y transeúnte.

¿No implica todo esto una concepción íntegra del ser humano? ¿No quieren establecer estas características de la conciencia que lo humano es una singularidad irreductible al ámbito meramente natural? Eso es precisamente lo que vengo a sostener que sostiene Arana y, en este sentido, tengo que señalar que aquellos que han desarrollado temáticamente esas peculiaridades de lo humano no se encuentran entre los naturalistas sino entre los que se llama humanistas. Y que esos mismos humanistas también han visto que la conciencia no se puede "explicar" por los mecanismos del "si... entonces" y por ello han determinado que lo único que se puede hacer es establecer otros cauces para "comprenderla": la conciencia es susceptible no de "explicación" sino de "comprensión". Esas notas se han desarrollado en el ámbito de la hermenéutica y de la fenomenología. Creo que es la virtud del libro de Arana señalar cómo la conciencia es algo irreductible al mundo natural, pero al mismo tiempo eso descubre su defecto o, al menos, la carencia que descubro: no el hecho de decir que no se puede explicar esa singularidad por medio de 
la ciencia natural y que jamás se podrá, que la conciencia está inexplicada y será inexplicable por ese paradigma, ya que eso lo hace el autor; lo que es su defecto es no abrir el camino - más bien lo cierra-a otras explicacionescomprensiones alternativas al negar que sean auténticas explicaciones. Es como si el físico negara la peculiaridad del fenómeno biológico porque efectivamente todo lo vivo está llamado a reducirse a polvo y por estar compuesto de partículas elementales. Y, sin embargo, hay una explicación propiamente biológica de la vida como la hay fenomenológica de la conciencia.

El hecho es que la conciencia es irreductible a la naturaleza y, además, tiene un ámbito en el que legisla y en el que su esencia puede ser puesta al descubierto: la narración de sí, su historicidad, su vivir en la metáfora y en el símbolo, la percepción del tiempo y de su contingencia. Su historicidad y su auto-interpretación en la historia, en resumidas cuentas. O diciéndolo tal y como otras veces lo hemos enunciado: su capacidad de apertura y su capacidad de auto-determinarse en su indeterminación, es decir, la capacidad de articular las estructuras de la subjetividad. Esa es la América que descubre Arana aunque él prefiera, para desesperación de algunos miembros de la tripulación, darse la vuelta una vez que la ha divisado porque no la considera fructífera como método para explorar un ámbito de realidad. Mi propuesta es que, al señalar que la conciencia es un fenómeno, también se la hace objeto de conocimiento aunque sea de otra forma. Y es que el ser humano "debe" conocerse a sí mismo: debe como acto moral y como esencia de su constitución en el sentido kantiano ("la ley moral en mí"). 


\section{Una propedéutica a la hermenéutica de la conciencia}

Lo que inicia la búsqueda del saber es el asombro. Pero el asombro no nace primero, como me parece que cree Arana, ante lo grandioso del mundo natural. Puede ser un asombro ante lo magnífico y lo sublime (en sentido también kantiano), pero más bien interpreto que es un asombro ante la propia finitud frente a la inmensidad del cosmos: el inmenso deseo de saber acerca de las cosas viene mediado por la conciencia de que no se sabe, de que el hombre es sustantiva y conscientemente "problema". Y, especialmente, de que no sabe orientarse entre las cosas y tiene que buscar la manera de hacerlo. Ello quiere decir que, según interpreto, la primera pregunta que hace el ser humano gira en torno de sí mismo y de su sentido y solo secundariamente problematiza el universo. No es un asombro ante el espectáculo grandioso de la naturaleza sino de resolver cuál es el sentido de lo humano en medio del mundo en el que habita. Busca originariamente una comprensión de la totalidad del ser donde él mismo tenga cabida y, también pero secundariamente, del cosmos en el que se ha encontrado existiendo. Arana ha sostenido en diversos lugares — siendo más aristotélico que cartesiano-que primero se constituye la Física y luego y, sobre ella, lo hace la Metafísica. Por eso afirma con rotundidad que el hundimiento de la Física de Aristóteles tiene que tener consecuencias necesarias en su Metafísica y que ésta no puede escapar impune al descalabro que su teoría sobre el ente móvil sufre en el inicio de la modernidad con el nacimiento del paradigma científico. Sin embargo, esa tesis creo que gira sobre un error: la ciencia primera (llamémosla así mejor que "meta-física" para no darle la razón a Arana ni siquiera en una 
terminología que, como se sabe, no es de Aristóteles) no se construye sobre la física sino que se realiza a la par que ella e incluso antes que ella porque el hombre es problema para el hombre antes que el universo físico. La ciencia primera es primera también en el tiempo. No es necesario tener una ciencia completa del ente móvil para tener una ciencia del ser ya que el ser humano en lo que está interesado, sobre todo, es en comprenderse a sí mismo como ente en el entorno global del ser. Él mismo está sometido a la contingencia de su propia fisicidad, pero la conciencia de ser físico y, como tal, contingente, escapa a la propia condición de ser físico y lo adentra en la categoría de ser hermenéutico, de ser que se problematiza y problematiza el mundo con el afán de descubrir su sentido. Apelo para esa interpretación no a Aristóteles sino al Heidegger de Ser y Tiempo, concretamente al que en el parágrafo 4 , al inicio mismo de esa obra, afirma lo siguiente:

El Dasein no es tan solo un ente que se presenta entre otros entes. Lo que lo caracteriza ónticamente es que a este ente le va en su ser este mismo ser. La constitución de ser del Dasein implica entonces que el Dasein tiene en su ser una relación de ser con su ser (Heidegger, 2003: 35).

No es que primero venga la Física y después se construya la Metafísica. Los saberes no funcionan ni como en el Corpus Aristotelicum ni como las disciplinas académicas han categorizado. La primera pregunta es del ser humano por su ser, es decir, intenta comprenderse a sí mismo en su finitud, es hermenéutica, y después surge todo lo demás. Cosa distinta es que las leyes de la naturaleza sean más uniformes que las leyes que rigen lo humano 
y que adelantemos antes en su comprensión que en la de lo humano mismo. Una cosa es el hecho del mayor progreso de las ciencias de la naturaleza y otra que el ser humano se haya esforzado por desarrollarlas primero en un afán metodológico de solucionar en primer lugar lo "fácil” para después ocuparse de lo "difícil", es decir, de sí mismo. Eso "fácil” es tan complejo que posiblemente no habríamos adelantado nada en milenios en la comprensión del ser humano si tuviéramos que esperar a que se solucionaran los problemas planteados por la comprensión del Universo. Y creo que algo hemos logrado en el entendimiento de nosotros mismos. La pregunta hermenéutica es la del ser que se juega su ser y que necesita orientación. Y se percata de que todo su esfuerzo debe dirigirse en esa dirección. Entre esos esfuerzos está también la ciencia natural como instrumento de elucidación del mundo físico en el que el hombre habita. Pero la pregunta no gira originalmente por el sentido del mundo sino por el sentido del hombre dentro del mundo.

Dentro de esas caracterizaciones hermenéuticas se ha entendido al ser humano como historia, como narración, como espíritu. En resumidas cuentas, como aquel que no se agota en haber "sido" sino en estar constantemente "siendo", un estar volcado hacia fuera porque el ser humano no está hecho interiormente sino que se hace haciendo y articula su subjetividad de forma transitiva y reflexiva transformando conscientemente el mundo en el que habita. Y mi pregunta es, ¿no son estas las características que asigna Arana a la conciencia? ¿No habla de creación, de trascendencia, y de extroversión? ¿Por qué niega entonces la función de "explicación-comprensión" de la conciencia a las disciplinas filosóficas que tradicionalmente se han ocupado de hacerlo? Y es que Arana ha descubierto la hermenéutica, ha captado la esen- 
cia de lo humano sin darse cuenta — creo- de que hay ámbitos donde se explica o comprende mejor que con la estructura del si...entonces. Se explica con la estructura de la interpretación conjunta que los seres humanos hacen de sí en un diálogo intersubjetivo perpetuo. Perpetuo porque el ser humano no es un "hecho" sino un "sentido" que se constituye reinterpretándose continuamente en la historia que le toca vivir. El problema que creo que se plantea es querer explicar al ser humano de la misma forma que a la naturaleza física, lo que es imposible. Pero al mismo tiempo no se considera la legitimidad explicativa de la hermenéutica quizás porque no se la vea a la misma altura que los desarrollos que ha logrado la ciencia natural. Mi pregunta sería, ¿es posible establecer puentes entre la explicación que proporciona la ciencia natural y la comprensión que ofrece de los fenómenos humanos la hermenéutica? ¿Deben ambas permanecer ajenas la una a la otra? ¿Deben deslegitimarse mutuamente? ¿Hay alguna de ambas que carezca de sentido "explicativo" o "comprensivo"? ¿Alguna de la que se pueda prescindir?

\section{Conclusión. El puente entre naturalismo y hermenéutica. Naturaleza y libertad}

Se necesita un puente cuando existen dos lugares físicos separados por un accidente natural intransitable: es necesario el puente para pasar de manera fácil y cómoda entre dos núcleos de población separados por un enorme río invadeable o por un precipicio. Pero, entre lo físico y lo humano, creo que las relaciones deben establecerse no mediante un puente, como si conectara dos 
realidades inconmensurables, sino como la superposición de dos estructuras que se requieren para existir pero que no pueden reducirse la una a la otra. Creo que la metáfora de la escalera de Wittgenstein es mejor que la del puente porque los dos campos de realidades que estamos considerando no están al mismo nivel sino uno —el humano- por "encima" del otro —el físico-natural一. Valga esa imagen espacial ya que no encuentro otra mejor.

El ámbito de lo humano se sitúa encima de la estructura de lo orgánico como ésta se sitúa sobre lo inerte. Son estructuras que aportan, cada una, novedad a lo anterior por lo que los métodos que sirven para explicar una no son suficientes para explicar las otras. No sabemos si lo orgánico surge de lo inerte y la conciencia de la evolución de la vida más allá que como postulado del programa naturalista. Explicar la conciencia desde lo biológico sería como intentar comprender los fenómenos vitales con el aparataje conceptual que ofrece la mineralogía. Arana se da cuenta de eso y expone sus conclusiones detalladamente con los interlocutores naturalistas que cree pertinentes: la conciencia no es objeto de las ciencias naturales. Pero el problema es que concibe que no existe otro tipo de explicación más que el que ellas proporcionan. El mérito de Arana es señalar el fenómeno pero, a mi juicio, se queda corto en su meritorio análisis porque lo humano, si no explicado, debe ser comprendido. Ya sabemos cómo el propio Wittgenstein concibió que de lo que no se podía hablar mejor era callarse: lo que no se puede explicar, mejor es dejarlo sin expresar. Como sabemos, Wittgenstein, después de escribir el Tractatus y de sentenciar lo anterior, se retiro a cultivar un huerto para predicar con el ejemplo. Pero eso no le impidió volver tras un tiempo para seguir gestando ideas que, a mi juicio, hacen del llamado segundo Wittgenstein un 
autor mucho más interesante que el primero. De lo que se trata no sea quizás de "explicar" lo humano como un hecho, pero sí se trata de entenderlo. Y solo la hermenéutica ha emprendido esa tarea. Habrá, pues, que prestarle atención.

Se ha intentado en la historia del conocimiento convertir en ciencias estrictas todos los saberes, incluso a la filosofía misma. Creo que eso es un error porque implica universalizar métodos de acceso a ciertos fenómenos particulares. Eso lo sabe bien Arana y lo demuestra en su obra, pero cree que no es necesaria la escalera porque lo humano debe quedar inexplicado. No solo no hay que tirar la escalera después de haber subido, ni siquiera era necesaria porque todo lo que se puede comprender con rigor es fenómeno natural. Sin embargo, me parece que si deseamos transitar de arriba abajo y de abajo arriba necesitamos esa escalera que nos da acceso a ambos campos de fenómenos. Y, quizás Arana no se ha dado cuenta, pero ha sido artífice de la construcción de la escalera misma poniendo de manifiesto que hay un ámbito de realidad inaccesible a la ciencia pero que necesita ser comprendido: que hay un fenómeno llamado conciencia que escapa del ámbito metodológico de la ciencia natural. Especialmente cuando esos dos campos existen y están desconectados es más necesaria que nunca esa escalera. Comprendo que, como filósofo de la naturaleza que es, Arana no quiera subirla y que desconfíe de antropólogos y metafísicos. Pero considero que su intento debe ser proseguido con coherencia y, por ello, otros tienen que tomar el relevo que lleve de la ciencia natural a la comprensión de los fenómenos humanos. La escisión entre ambos campos será menor a partir de su libro: los naturalistas no podrán decir que es una tarea inútil ni los humanistas decir 
que es algo obvio. Ha conseguido señalar los límites para que otros sigan construyendo conocimiento sobre fenómenos que resultaban desligados del cuerpo general de los conocimientos. Enhorabuena por tan crucial aportación.

\section{Referencias bibliográficas}

J. Arana, La conciencia inexplicada. Ensayo sobre los limites de la comprensión naturalista de la mente, Madrid, Biblioteca Nueva, 2015.

M. Heidegger, Ser y Tiempo, Madrid, Trotta, trad. de Jorge Eduardo Rivera, 2003.

Francisco Rodríguez Valls rvalls@us.es 